\title{
Reconhecimento contábil da degeneração de ativos biológicos para a produção no cultivo de árvores frutíferas
}

Accounting recognition of degeneration of biological assets for production in growing fruit trees

Reconocimiento contable de la degeneración de activos biológicos para la producción en el cultivo de árboles frutales

\author{
Allana Souza Martins \\ Acadêmica do curso de Ciências Contábeis pela Universidade Federal de Rondônia \\ Endereço: Rua Paulo Rogério Fornari, ${ }^{\circ}$ 502, Centro \\ CEP: 76.980-000 - Vilhena/RO - Brasil \\ E-mail: allana_smartins@hotmail.com \\ Telefone: (69) 3322- 9968
}

\section{Deyvison de Lima Oliveira}

Doutor em Administração pela Universidade Federal do Rio Grande do Sul

Professor dos Cursos de Ciências Contábeis e Administração da Universidade Federal de Rondônia

Endereço: Av. 02, Rotary Clube, $\mathrm{n}^{\circ}$ 3756, Setor 10, Jardim Social

CEP: 76980-000 - Vilhena/RO - Brasil

E-mail: deyvilima@gmail.com

Telefone: (69) 3321-3072

Artigo recebido em 12/12/2013. Revisado por pares em 23/01/2014. Reformulado em 17/02/2014. Recomendado para publicação em 04/03/2014 por Sandra Rolim Ensslin (Editora Científica). Publicado em 08/04/2014. 


\title{
Resumo
}

Este trabalho apresenta uma proposta de fluxo contábil da degeneração na fruticultura com base nos procedimentos normatizados pelo CPC 27 e CPC 29, confirmando a possibilidade de mensuração das transformações biológicas nas atividades rurais em acordo com as normas atuais de Contabilidade e auxiliando na redução de distorções na mensuração do patrimônio da entidade. Para isso, o estudo de casos múltiplos foi utilizado como procedimento metodológico. Foram aplicadas entrevistas, observações diretas e análises documentais em empreendimentos cultivadores de árvores frutíferas. Nos resultados obtidos, consta uma comparação do reconhecimento da degeneração com base nos dois métodos de mensuração de ativos: custo e valor justo.

Palavras-chave: Ativo biológico para a produção. Árvore frutífera. CPC 29. Degeneração. Fluxo de caixa descontado.

\begin{abstract}
This work presents a proposal of accounting flow of degeneration in fruit production based on standardized procedures by CPC 27 and CPC 29, confirming the possibility of measurement of biological transformations in rural activities in accordance with current accounting standards and helping to reduce distortions in measurement of the assets of the entity. For this, the multiple case study was used as the method. Interviews, direct observations and document analyzes developments growers of fruit trees were applied. Results shown in a comparison of the recognition of degeneration based on the two methods of measuring assets: cost and fair value.
\end{abstract}

Keywords: Biological assets for production. Fruit ttree. CPC 29. Degeneration. Discounted cash flow.

\section{Resumen}

Este trabajo presenta una propuesta de flujo contable de la degeneración en la fruticultura con base en los procedimientos estandarizados por el CPC 27 y por el CPC 29, confirmando la posibilidad de medición de las transformaciones biológicas en las actividades rurales de acuerdo a las normas actuales de Contabilidad y auxiliando en la reducción de distorsiones en la medición del patrimonio de la entidad. Para ello, el estudio de casos múltiples fue utilizado como procedimiento metodológico. Fueron aplicadas entrevistas, observaciones directas y análisis documentales en emprendimientos cultivadores de árboles frutales. En los resultados obtenidos, consta una comparación del reconocimiento de la degeneración con base en los dos métodos de medición activos: costo y valor justo.

Palabras clave: Activo biológico para la producción. Árbol frutal. CPC 29. Degeneración. Flujo de caja descontado. 
1 Introdução

Com a evolução da humanidade, a atividade rural se tornou muito mais que uma prática para subsistência e hoje está entre as maiores atividades que movimentam a economia mundial (PEREIRA et al., 2010; AZEVEDO, 2011; FIGUEIREDO; SANTOS; LIMA, 2012; MARION, 2012).

Junto com a crescente importância do agronegócio para a economia e perante o processo de convergência da contabilidade brasileira aos padrões internacionais, cresce também a demanda por profissionais capacitados em evidenciar as transformações ocorridas nas atividades rurais (WANDERLEY; SILVA; LEAL, 2012), bem como com a competência de interpretação das informações fornecidas pela contabilidade desse setor, que servem como instrumento de tomada de decisão (CREPALDI, 2006).

A falta desse tipo de profissionais faz com que parte dos produtores rurais não utilize as informações geradas pela contabilidade para melhorar a gestão de seus empreendimentos. Isso se deve à dificuldade de que os contadores têm relacionada ao entendimento e à aplicação do valor justo (SILVA; SILVA; DENBER, 2011), tornando essa uma das principais causas da forte resistência da adoção dos pronunciamentos contábeis pelas empresas brasileiras.

Nesse contexto, o Comitê de Pronunciamentos Contábeis (CPC) aprovou o Pronunciamento Técnico CPC 29, que é basicamente uma tradução da norma internacional "IAS 41 - Agriculture" publicada pelo IASB (International Accounting Standard Board), segundo a qual o valor justo também deve servir de base de mensuração para os ativos biológicos e produtos agrícolas (SILVA FILHO et al., 2012).

O CPC aprovou também o pronunciamento técnico CPC 27, que prevê a mensuração de ativos pelo método de custos. Esse método é utilizado por algumas empresas brasileiras como alternativa primordial contestando a abordagem do CPC 29 de que o método de custo deve ser utilizado em últimas circunstâncias. A questão é que a adoção de taxas fiscais de depreciação evidencia que o processo de convergência das normas contábeis ainda não ocorre na totalidade, conforme constatou Freire et al. (2012). A depreciação ganha relevância a partir do momento em que a entidade apresente direcionamento para os critérios estabelecidos no CPC 27 (2009a), e não por legislações fiscais específicas.

Sabe-se que todo ativo biológico passa por transformação biológica que, de acordo com Silva Filho, Machado e Machado (2013), assim como o CPC 29 (2009b), compreende o processo de crescimento, degeneração, produção e procriação que causam mudanças qualitativa e quantitativa no ativo biológico. Este artigo dá ênfase, principalmente, à degeneração dos ativos biológicos para produção por meio de um estudo de caso no setor de fruticultura.

O impacto da degeneração dos ativos biológicos para a produção na contabilidade do agronegócio é um item que merece destaque nos relatórios contábeis visto que esses ativos perdem o valor a cada ano em decorrência do desgaste natural que sofrem, e, consequentemente, a capacidade de geração de benefícios para a entidade também é reduzida. Assim, a grande dificuldade é fazer com que o valor dos ativos biológicos registrados nas demonstrações contábeis reflita a realidade da entidade.

O estudo da aplicabilidade dos CPCs ao setor de fruticultura é diferencial e busca verificar qual será o efeito da adoção dos pronunciamentos técnicos CPC 27 e CPC 29 em empreendimentos que possuem, em seus ativos biológicos, uma de suas principais fontes de receita. 
Em linhas gerais, o que leva a discorrer sobre o tratamento contábil dado ao desgaste do ativo biológico para a produção é o fato de a degeneração desse tipo de ativo ser um item relevante no atual contexto do agronegócio, em virtude do processo convergência das normas brasileiras de contabilidade aos padrões internacionais (WANDERLEY; SILVA; LEAL, 2012) e de haver poucos referenciais teóricos que abrangem essa área de pesquisa.

Justifica-se essa escolha devido à existência de estudos na área de contabilidade do agronegócio que dão ênfase sobre a forma de mensuração e contabilização da valoração dos ativos biológicos em geral e um reduzido número de investigações que discutem a degeneração desses ativos. Dentre esses estudos, citam-se Azevedo (2011); Oliveira, Ferreira e Porto (2012); Silva, Silva e Denberg (2011) e Wanderley, Silva e Leal (2012).

No cenário da contabilidade do agronegócio, em harmonia com as normas internacionais, ainda existem muitos itens a serem explorados e diversos conceitos a serem concretizados, visto que uma das principais dificuldades a ser enfrentada refere-se à necessidade imediata de uma mudança nos valores normativos até então existentes (SILVA; SILVA; DENBER, 2011). As pesquisas acadêmicas nessa área são extremamente relevantes como instrumento de multiplicação de informações. Nesse sentido, ressaltamos a contribuição deste trabalho científico.

Dessa forma, o objetivo geral da pesquisa restringe-se em evidenciar, a partir do manejo de árvores frutíferas, a contabilização da degeneração natural do ativo biológico para a produção, mensurado a valor de custos, e propor o reconhecimento contábil da degeneração do ativo mensurado a valor justo, por meio de um comparativo adotando os procedimentos normatizados pelo CPC 27 e CPC 29.

O artigo está estruturado em mais quatro seções, além desta introdução. Na seção 2, apresenta-se o referencial teórico, que inclui basicamente assuntos relacionados ao conceito, características e formas de mensuração de ativos biológicos para a produção, além do modelo conceitual de pesquisa; na seção 3, encontram-se os procedimentos metodológicos adotados na pesquisa; nas seções 4 e 5, são apresentados os resultados obtidos com a pesquisa e as considerações finais, respectivamente.

\section{Referencial Teórico}

Este referencial teórico descreve os conceitos e características dos ativos biológicos para produção, bem como as formas de mensuração e as peculiaridades da degeneração sofrida por esses ativos.

\subsection{Conceitos e Características de Ativos Biológicos}

O CPC 29 - Ativo Biológico e Produto Agrícola, em seu item 5, traz um conceito simplificado de ativo biológico: "é um animal ou uma planta, vivos". Na visão de Oliveira, Ferreira e Porto (2012), ativo biológico é o nome atribuído a qualquer animal ou planta que sofre transformações biológicas para gerar o produto agrícola. De acordo com Azevedo (2011), ativos biológicos são controlados pela empresa como resultado de eventos passados e dos quais se esperam que futuros benefícios resultem para a entidade.

$\mathrm{Na}$ contabilidade agrícola, para determinar a característica de um ativo biológico, deve-se considerar o tipo de cultura existente que pode ser temporária ou permanente

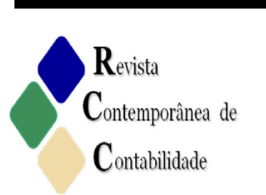

ISSN 2175-8069, UFSC, Florianópolis, v. 11, n. 22, p. 73-94, jan./abr. 2014 
(MARION, 2012). A cultura temporária caracteriza-se por ter o período de vida curto e estar sujeita ao replantio após a colheita, é o caso da soja, milho, arroz, feijão, entre outras. Já a cultura permanente tem como principal característica a possibilidade de proporcionar mais de uma colheita ou produção, a exemplo de, praticamente, todas as frutas arbóreas (manga, laranja, goiaba, mamão etc.).

O CPC 29, em seu item 44, traz um conceito de tipos de culturas semelhante ao abordado por Marion (2012), porém utiliza uma nomenclatura diferente: para a cultura temporária, utiliza-se ativo biológico consumível, e para a cultura permanente, ativo biológico para a produção. Essa é a nomenclatura utilizada no decorrer deste artigo.

Pode-se dizer que ativos biológicos consumíveis são aqueles que são colhidos como produto agrícola ou vendidos como ativos biológicos; e ativos biológicos, para a produção, são "fornecedores" de produtos agrícolas, mas não podem ser colhidos como tal (CPC, 2009b).

\subsection{Mensuração do Ativo Biológico e Formação do Imobilizado}

Hendriksen e Breda (2007) definem mensuração, na contabilidade, como sendo a atribuição de valores monetários aos diversos itens que compõem o patrimônio de uma entidade, ou seja, é uma aproximação numérica das propriedades de um objeto. Dessa forma, pode-se concluir que mensurar significa medir, determinar o valor de algo.

Nesse contexto, é possível dizer que medir ou determinar o valor de um ativo biológico exige muito conhecimento e controle do ativo em questão, considerando que ele está em constante transformação biológica. Portanto, o Comitê de Pronunciamentos Contábeis emitiu, em 2009, o CPC 29 correlacionado à norma internacional IAS 41 -Agriculture, que objetiva a mensuração de ativos biológicos e produtos agrícolas pelo método do valor justo, comumente conhecido como valor de mercado.

A $I A S 41 / \mathrm{CPC} 29$ foi a primeira norma internacional de contabilidade voltada para o setor agrícola e marcou radicalmente o tratamento contábil dado aos ativos biológicos e produtos agrícolas, uma vez que a base de mensuração desses ativos passou de uma contabilidade considerada tradicional (custo histórico) para a contabilidade a valor justo (SILVA FILHO et al., 2012; SILVA FILHO; MACHADO; MACHADO, 2013).

Considerando a base de mensuração para os ativos biológicos praticada no Brasil, sabe-se que, até a aprovação do CPC 29, não havia uma norma ou qualquer orientação contábil específica para os ativos biológicos. Assim, a maioria das empresas brasileiras de capital aberto contabilizava os ativos biológicos com base no valor de custo (SILVA FILHO; MACHADO; MACHADO, 2013).

Cabe ressaltar que, em conformidade ao CPC 29, produto agrícola é o produto colhido dos ativos biológicos e, após o momento da colheita, o produto agrícola ainda é avaliado conforme o referido pronunciamento, porém essa norma não trata do processamento ou transformação do produto agrícola após a colheita - momento em que deve ser observado o CPC 16 - Estoques ou outro Pronunciamento Técnico (CPC, 2009b). Nesse contexto, o presente artigo prioriza o tratamento contábil do ativo biológico para a produção e suas transformações biológicas, especificamente, a sua degeneração.

Os ativos biológicos para a produção são registrados no ativo não circulante no grupo de imobilizados por possuírem as três características básicas que definem os itens constantes nesse grupo: são capazes de gerar benefícios futuros para a entidade; são utilizados nas 
atividades operacionais; e têm vida útil de longa duração (IUDÍCIBUS et al., 2010). Além disso, o CPC 27 (2009a), em seu item 6, enfatiza que um ativo imobilizado corresponde ao item tangível que é mantido pela entidade com o fim de ser utilizado para produzir ou fornecer mercadorias por mais de um período.

Nesse sentido, o CPC 29 menciona que um ativo biológico só pode ser reconhecido pela entidade quando ela possuir o controle do ativo como resultado de eventos passados; quando for provável que futuros benefícios econômicos associados com o ativo fluirão para a entidade; e quando o valor justo do ativo puder ser mensurado de forma confiável.

O CPC 27 estabelece, em seu item 16, que o valor do ativo imobilizado a ser reconhecido nas demonstrações contábeis corresponde ao valor de aquisição ou construção do bem, somando-se a esse valor outros custos diretamente atribuíveis, que são entendidos como os custos necessários para colocar o ativo imobilizado no local e nas condições em que ele possa começar a gerar benefícios para a entidade.

Por outro lado, o CPC 29, em seu item 12, enfatiza que o ativo biológico deve ser reconhecido inicialmente e, ao final de cada período de competência, pelo seu valor justo menos despesa de venda, exceto quando o valor justo para os ativos biológicos não puder ser mensurado de forma confiável. Com isso, observa-se que a mensuração do ativo biológico e, consequentemente, a formação do imobilizado apresentam-se sob duas vertentes: o valor de custo estabelecido pelo CPC 27 e o valor de mercado (valor justo) definido pelo CPC 29.

Porém o CPC 29 afirma que tanto o ativo biológico quanto o produto agrícola colhido desses ativos devem ser mensurados ao valor justo menos despesas estimadas de vendas, exceto para os casos em que o valor justo não pode ser mensurado de forma confiável. Nesse caso, o CPC 27, ou outro pronunciamento técnico adequado, deve ser aplicado. O CPC 29 é um pronunciamento técnico específico para ativos biológicos e produtos agrícolas, portanto deve ser adotado em sua íntegra no que se refere ao tratamento contábil de ativos biológicos.

Marion (2012) afirma que a Contabilidade das atividades rurais estava sendo tratada da mesma forma que as atividades industriais no tocante à determinação do ciclo operacional e de taxas de depreciação, destinando-se aos ativos biológicos o mesmo tratamento dado às máquinas, implicando a depreciação pelo prazo de vida útil do ativo com taxas estimadas pela legislação fiscal. Nessa linha, o pronunciamento técnico 29 foi emitido justamente com o propósito de diferenciar o tratamento contábil das atividades rurais daquele dado a outras atividades, visto que a produção rural possui características específicas e, dessa forma, deve ser tratada nas suas especificidades.

Contudo, Wanderely, Silva e Leal (2012) reafirmam a exceção trazida pelo CPC 29 (item 30), que caso não haja valor de mercado ou as formas de mensuração do valor justo não forem confiáveis, o custo histórico ainda deverá ser usado como forma de mensuração de ativos biológicos.

\subsection{Degeneração pelo Método de Mensuração do Custo à luz do CPC 27}

O método de mensuração de ativos imobilizados pelo custo está previsto no CPC 27, que também faz parte do processo de harmonização contábil brasileiro.

Esse método está inteiramente relacionado aos elementos componentes do ativo que foram adquiridos sem que houvesse qualquer alteração em seu valor. Esses elementos são mensurados pelos valores que foram pagos na aquisição, ou que constam nas notas fiscais de compra, e utilizados normalmente na mensuração de estoques e imobilizados. Somam-se ao

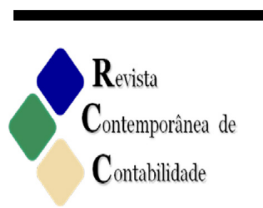

ISSN 2175-8069, UFSC, Florianópolis, v. 11, n. 22, p. 73-94, jan./abr. 2014 
valor de aquisição apenas os custos diretamente atribuíveis que correspondem a quaisquer custos para colocar o ativo no local e condição necessária para que seja capaz de funcionar, ou seja, gerar benefícios para a empresa (CPC 27).

As vantagens do método de mensuração pelo custo são objetividade, verificabilidade e representatividade do valor por meio do qual o ativo foi adquirido. Contudo, sua principal desvantagem é o fato de que o valor pode deixar de ser representativo com o passar do tempo em função das mudanças de preços, da desclassificação tecnológica dos ativos, motivada pela aparição de equipamentos mais modernos, e da redução do tempo de vida útil do ativo (HENDRIKSEN; BREDA, 2007). Dessa forma, o CPC 29 prevê a mensuração pelo método de custos apenas nos casos em que o valor justo de um ativo biológico não esteja disponível no mercado, e as alternativas para estimá-lo não forem claramente confiáveis. Se existir mercado ativo para o ativo biológico, o valor justo deve ser usado como método de mensuração (CPC 29).

A forma de degeneração de ativos imobilizados é trazida pelo CPC 27 como depreciação. Esse pronunciamento enfatiza que os principais itens que devem ser considerados na contabilização de um ativo imobilizado é o reconhecimento inicial, a determinação do valor contábil e o valor referente à depreciação ou perdas por desvalorização do ativo. A forma de se contabilizar esse desgaste condiz com padrões de depreciação já adotados na contabilidade das empresas brasileiras, ou seja, pelo método linear que resulta em despesa (ou custo) constante durante a vida útil do ativo (CPC 27).

Porém o CPC 27 menciona também, em seu item 62, que o método de depreciação por unidades produzidas, que resulta em despesa baseada no uso ou produção esperados, também pode ser usado. Dessa forma, a entidade deve selecionar o método que melhor reflita o padrão do consumo dos benefícios econômicos futuros gerados pelo ativo.

A depreciação de um ativo imobilizado se inicia quando este está pronto para uso e cessa quando não existem mais expectativas de benefícios econômicos futuros com a utilização de tal ativo (CPC 27). Segundo Marion (2012), no caso de ativos biológicos para a produção, a depreciação passa a incidir sobre a cultura logo após a primeira colheita e, quando o número de anos de produção da árvore se encerra, a depreciação para de incidir sobre esse ativo. A taxa de depreciação do ativo biológico para a produção de frutos deve ser estabelecida por agrônomos ou pelos próprios agricultores que conhecem a quantidade de anos de produção desse ativo, podendo estabelecer o prazo de vida útil.

A adoção do método de depreciação proporcionalmente à produção estimada, ou método de unidades produzidas, é vantajosa, visto que nos períodos em que a produção for menor o valor referente à depreciação também será menor e vice-versa, evitando oscilações nos resultados de vários ciclos operacionais em decorrência da redução excessiva do lucro em períodos de baixa produção (MARION, 2012).

\subsection{Degeneração pelo Método de Mensuração ao Valor Justo}

Além da base de mensuração descrita anteriormente (método de custo), existem outras formas de mensurar o valor de um ativo, entre elas está o valor justo ou fair value (SILVA FILHO et al., 2012). Argilés, Garcia-Blandon e Monllau (2011) afirmam que grandes grupos de Contabilidade e instituições em todo o mundo, tais como o International Accounting Standards Board (IASB), principal órgão normatizador contábil do mundo, e o Financial 
Accounting Standards Board (FASB) têm incentivado a adoção do valor justo como padrão de mensuração de ativos.

O CPC 29, em seu item 8, enfatiza que "valor justo é o valor pelo qual um ativo pode ser negociado, ou um passivo liquidado, entre partes interessadas, conhecedoras do negócio e independentes entre si, com a ausência de fatores que pressionem para a liquidação da transação ou que caracterizem uma transação compulsória”.

Para Wanderley, Silva e Leal (2012), como os ativos biológicos estão sujeitos a transformações biológicas que afetam o seu valor de forma significante, o método de mensuração pelo custo se torna incapaz de refletir fielmente os ganhos ou as perdas de valor.

O CPC 29 afirma que a transformação biológica resulta em várias mudanças físicas no ativo biológico ou produto agrícola, podendo cada uma delas ser observada e mensurada. Essas mudanças físicas têm relação direta com os benefícios econômicos futuros dos ativos. A alteração no valor justo de um ativo biológico devido à colheita também atende ao requisito de uma mudança física.

De acordo com o CPC 29, um dos eventos resultantes da transformação biológica é a degeneração que corresponde à redução na quantidade ou deterioração na qualidade do animal ou da planta.

Os ganhos ou as perdas decorrentes da avaliação de ativos biológicos pelo valor justo menos despesas estimadas de venda devem ser reconhecidos no resultado do exercício em que ocorreram (CPC 29). No caso da degeneração de ativos biológicos para a produção, as perdas têm mais evidência, visto que afetam diretamente o resultado da produção de forma negativa.

As perdas provenientes da mudança no valor justo dos ativos biológicos podem ser comparadas à figura da depreciação no método de mensuração pelo custo, visto que tanto uma como a outra são redutoras de ativos na contabilidade do agronegócio.

$\mathrm{Na}$ fruticultura, a principal diferença é que os custos com depreciação da árvore frutífera (ativo biológico para a produção) podem ser incluídos no valor contábil dos frutos (produtos agrícolas) sem que essa depreciação altere diretamente o resultado final da produção (CPC 27) - no caso de se mantiverem os produtos em estoques. Já as perdas decorrentes da avaliação de ativos biológicos a valor justo são diretamente registradas no resultado do exercício, como prevê o CPC 29, mesmo antes da ocasião da venda dos produtos agrícolas.

\subsection{Modelo Conceitual}

Com base na revisão de literatura da seção 2, um modelo conceitual, para representar a degeneração de ativos biológicos na fruticultura, é apresentado.

Cumpre ressaltar que a redução do potencial produtivo do ativo biológico, que é a causa da depreciação no método de custos, também é um fator que reduz o valor de mercado do ativo no método de valor justo. Porém a alteração no valor de mercado não influencia o potencial produtivo do ativo. 
Figura 1 - Modelo conceitual da degeneração do ativo biológico para a produção

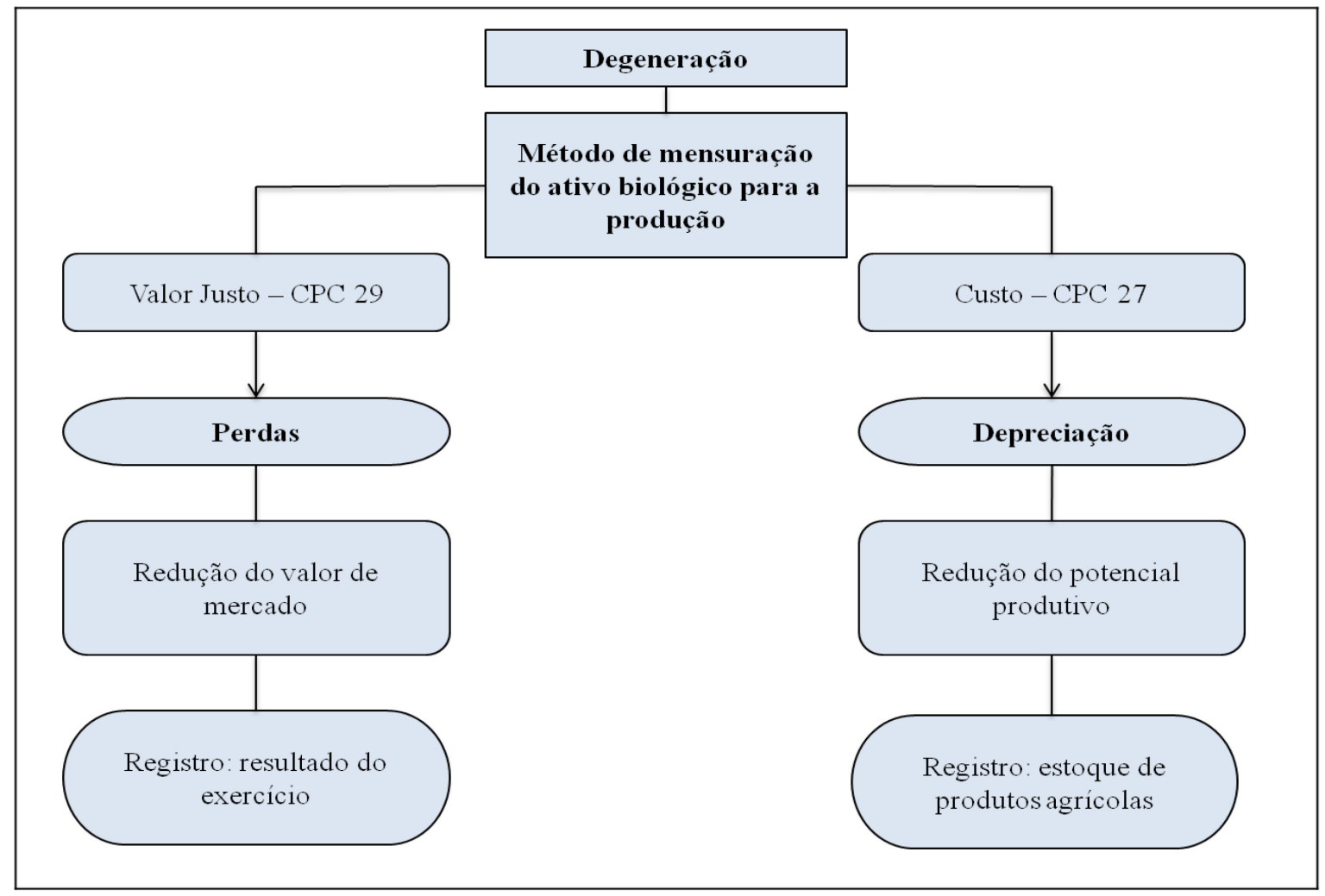

Fonte: Elaborado com base na literatura.

\section{Método}

O procedimento metodológico adotado nesta pesquisa é o estudo de caso, que é definido por Yin (2010, p. 39) como "uma investigação empírica que investiga um fenômeno contemporâneo em profundidade e em seu contexto de vida real". Para Severino (2007, p. 121), o estudo de caso é uma pesquisa concentrada no estudo de um caso particular considerado representativo de um conjunto de casos semelhantes.

A pesquisa de estudo de casos compreende um método abrangente, amparando toda a lógica do projeto, as técnicas de coleta de dados e as abordagens específicas à análise dos dados (YIN, 2010). Esse tipo de pesquisa tem sido utilizado na literatura de contabilidade do agronegócio, a exemplo de Oliveira, Ferreira e Porto (2012); Soares Brasil et al. (2012), entre outros.

Como se optou por estudar mais de um caso particular, o procedimento metodológico utilizado foi o estudo de casos múltiplos, defendido por Yin (2010, p. 41). Segundo o autor, quando um estudo contém mais do que um único caso, ele utiliza um projeto de casos múltiplos.

Para Yin (2010, p. 85), quando há a opção de escolha entre projetos de casos únicos ou múltiplos, os casos múltiplos devem ser preferidos. Nos estudos de casos múltiplos, as chances de realização de um bom estudo são maiores, visto que há a possibilidade de replicação direta, e as conclusões analíticas são mais substanciais. 


\subsection{Coleta de Dados}

Como instrumento de coleta de dados foram utilizadas três fontes de evidência que possibilitaram melhor triangulação entre os dados (YIN, 2010). A primeira fonte adotada foram as entrevistas focadas com produtores rurais, que cultivam árvores frutíferas em empreendimentos localizados no Cone Sul do estado de Rondônia.

Segundo Yin (2010), a entrevista é uma das fontes de informação mais importante para o estudo de caso, devido ao fato de que a maioria delas é sobre assuntos humanos ou eventos comportamentais e os entrevistados podem fornecer insights importantes sobre isso.

Este artigo busca levantar informações sobre as mudanças sofridas por ativos biológicos para a produção, especificamente a degeneração, tratando-se então de um evento comportamental. Nesse sentido, a aplicação de entrevistas foi utilizada como principal fonte de evidência.

As entrevistas abrangeram questões relacionadas às características do cultivo, identificação dos custos necessários para o negócio e avaliação de mercado do ativo, proporcionando o levantamento de informações que auxiliaram no conhecimento das peculiaridades do ativo biológico "árvore frutífera" e do contexto operacional em que ele está inserido. As informações adquiridas com base na aplicação de entrevistas foram então indispensáveis para a mensuração e o reconhecimento da degeneração na fruticultura.

A segunda e a terceira fontes correspondem à observação direta e à análise documental, respectivamente. A observação direta foi escolhida pelo fato de que o estudo de caso ocorreu no ambiente natural dos casos em questão, criando uma oportunidade para a observação. De acordo com Yin (2010), as observações diretas podem ser feitas durante a visita de campo e em ocasiões em que outras fontes de evidência estão sendo aplicadas, como, por exemplo, no momento das entrevistas. O autor ressalta ainda que a evidência observacional é importante por proporcionar informações adicionais sobre o objeto que está sendo estudado.

Já a escolha da análise documental, que, nesta pesquisa caracterizou-se por análise de notas fiscais de venda de produtos agrícolas e alguns cadernos de anotações da produção, é justificada por ser uma fonte de evidência relevante para todos os tópicos de estudo de caso, como corrobora Yin (2010). Segundo o autor, o uso mais importante da análise documental é confirmar e aumentar a evidência de outras fontes, além disso a revisão de documentos relevantes desempenha um papel fundamental em qualquer plano de coleta de dados.

As três fontes de evidência foram aplicadas com o objetivo de confirmar o que estava sendo investigado visto que as fontes individuais não são recomendadas para a condução de estudos de casos (YIN, 2010).

\subsection{Análise de Dados}

Com base nas informações coletadas a partir da aplicação das fontes de evidência, que ocorreu no mês de agosto de 2013, procedeu-se à análise de conteúdo. As entrevistas foram o principal instrumento de coleta de dados. Tendo por base a obra de Bardin (2011), foi realizada análise de conteúdo de entrevistas e de outras fontes de evidência, objetivando a inferência de conhecimentos sobre evidenciação e contabilização da degeneração de árvores 
frutíferas pelo método de mensuração do custo e a proposição da contabilização da degeneração pelo método de mensuração a valor justo, que é o objetivo basilar da pesquisa.

Bardin (2011) define análise de conteúdo como sendo um conjunto de técnicas de análise das comunicações que visa, por procedimentos sistemáticos e objetivos de descrição do conteúdo das mensagens, obter indicadores quantitativos ou qualitativos que permitam a inferência de conhecimentos relativos às condições de produção e recepção dessas mensagens.

Para a autora, "a análise de conteúdo de entrevistas é muito delicada" (BARDIN, 2011, p. 90). Esse material verbal exige o domínio de uma habilidade de análise muito maior do que a análise de questões abertas ou de documentos impressos (BARDIN, 2011). Assim, a adoção de entrevistas, como principal fonte de evidência, enriquece os resultados da pesquisa.

\section{Resultados, Discussão e Proposta de Reconhecimento}

\subsection{Descrição dos Casos}

A partir da escolha das fontes de evidência, procedeu-se à elaboração do protocolo de estudo de casos no intuito de direcionamento do investigador para o problema pesquisado. $\mathrm{O}$ protocolo de estudos de casos foi aplicado em cinco empreendimentos localizados no Cone Sul do estado de Rondônia cuja principal atividade é a fruticultura.

No primeiro caso pesquisado, predominava a produção de mamão de várias espécies e em grande quantidade, possuindo cerca de 250 árvores que chegavam a produzir, em média 3.000 , unidades da fruta diariamente. Porém esse primeiro caso foi utilizado como pré-teste para refinamento do roteiro de entrevistas. A partir desse primeiro caso, foi possível identificar quais aspectos, constantes no protocolo de estudo de casos, seriam apropriados na busca de solução ao problema proposto. Dessa forma, o roteiro de entrevistas foi ajustado com exclusão de algumas questões e alteração de outras, e só então se deu seguimento aos demais casos que caracterizaram esta pesquisa.

Entre os quatro casos, três são caracterizados pela produção de goiaba de várias espécies e um pela produção de laranjas. Porém, ao final da coleta de dados, optou-se por descartar a produção de laranjas, considerando não ser representativo no conjunto de casos estudados devido à baixa quantidade de árvores em processo de produção se comparada aos demais empreendimentos - o que resulta em apenas $0,87 \%$ do total de árvores frutíferas constantes no conjunto dos quatro casos. Além do mais, os empreendimentos cuja produção agrícola principal é a de goiabas teve predominância entre os casos, totalizando $75 \%$ deles, tornando assim o cultivo de goiabas representativo para este estudo de casos - o que contribui para a análise das peculiaridades produtivas e o alcance do objetivo da pesquisa. Dessa forma, restaram três empreendimentos para a realização do estudo de casos.

Os produtores rurais entrevistados possuem larga experiência com a fruticultura, com uma média de 15 anos de prática com o manejo de árvores frutíferas, e pertencem à classe de pequenos produtores. As variedades de espécies de árvores frutíferas constantes nas propriedades são muitas, mas sempre com predominância de uma espécie de fruta por haver produção e comercialização desta em maior quantidade. Segundo Marion (2012), nos casos de empresas que possuem suas culturas diversificadas e apresentam colheitas em diferentes períodos do ano, recomenda-se que o ano agrícola seja determinado em função da cultura que 
prevaleça economicamente. Por isso, as entrevistas foram focadas para essas espécies predominantes devido à sua representatividade na renda familiar dos produtores pesquisados.

Nesses empreendimentos, são cultivadas várias árvores frutíferas como limoeiro, abacateiro, jambeiro, entre outros, mas predomina a produção de goiaba de espécies variadas. O mercado consumidor do produto é local, ou seja, a comercialização ocorre na mesma cidade de produção, e, nos três casos, os produtores têm gastos com transporte para entrega dos produtos.

Porém os casos não se assemelham em todos os aspectos. No Quadro 1, constam as principais diferenças entre eles.

Quadro 1 - Principais características dos casos estudados

\begin{tabular}{|l|l|l|l|}
\hline \multicolumn{1}{|c|}{ Principais características } & \multicolumn{1}{|c|}{ Caso 1 } & \multicolumn{1}{c|}{ Caso 2 } & \multicolumn{1}{c|}{ Caso 3 } \\
\hline Tempo de experiência do produtor & 13 anos & 16 anos & 17 anos \\
\hline Quantidade de goiabeiras em processo de produção & 1.800 árvores & 300 árvores & 200 árvores \\
\hline Quantidade média de frutos colhidos por safra agrícola & $140.000 \mathrm{~kg}$ & $600 \mathrm{~kg}$ & $300 \mathrm{~kg}$ \\
\hline Tempo médio de vida útil das goiabeiras & 10 anos & 17 anos & 10 anos \\
\hline
\end{tabular}

Fonte: Dados da pesquisa.

Observa-se, no Quadro 1, que o tempo de vida útil das goiabeiras é a principal distinção entre as características dos casos, visto que, no Caso 2, esse período é muito maior se comparado aos outros casos. De acordo com os produtores rurais entrevistados nos casos 1 e 3, o cuidado com o processo de adubação, rega e poda das árvores pode fazer com que as goiabeiras durem muito mais tempo do que a média estipulada por eles. Essa diferença na vida útil pode ser justificada por cuidados adicionais do produtor do caso $2 \mathrm{com}$ as árvores. Além do mais, em todos os casos estudados, a produção de goiabas é de espécies variadas, portanto a diversidade de espécies cultivadas não fundamenta a diferença no período de vida útil.

\subsection{Agronegócio do Cultivo de Arvores Frutíferas: Peculiaridades}

Com base no CPC 29, as árvores frutíferas são consideradas ativos biológicos para a produção por possuírem as características básicas desse grupo de ativos. Essas características estão citadas no item 1.2 deste artigo. As frutas produzidas por esses ativos biológicos são produtos agrícolas e, após a colheita, há os produtos resultantes do processamento, as frutas processadas, por exemplo (SILVA FILHO et al., 2012).

Segundo Silva, Silva e Denber (2011), "as normas do IASB [...] trazem definições e regras mais amplas que se aplicam às mais variadas situações, sem especificar o tratamento dispensável a cada uma delas". Partindo desse pressuposto, conclui-se que o CPC 29 trata dos ativos biológicos e produtos agrícolas de forma generalizada, necessitando de pesquisas e trabalhos científicos que abrangem ramos específicos do agronegócio, evidenciando as 
peculiaridades existentes em cada um desses ramos, mas baseando-se nos conceitos amplos trazidos pelas normas internacionais.

A fruticultura é um ramo específico do agronegócio e, segundo Marion (2012), é caracterizada como uma atividade agrícola. A necessidade de um estudo sobre a forma de contabilização das transformações biológicas sofridas pelo ativo biológico para produção de frutas é urgente visto que esse tipo de produção tem se destacado na economia mundial (PEREIRA et al., 2010).

A análise dos dados possibilitou a observação de alguns pontos relevantes no manejo de árvores frutíferas, como o período de safra agrícola, por exemplo. No caso 1, a safra tem duração de oito meses que engloba o período de outubro a maio, e as colheitas são feitas diariamente nesse ínterim. No caso 2, a colheita é feita diariamente ou semanalmente, e o período de safra agrícola vai de outubro a janeiro. Já no caso 3 , o período de maior produção engloba os meses de dezembro a janeiro quando são feitas colheitas diariamente e, fora dessa época, a quantidade de produção por goiabeira é pequena. Porém esse foi o único empreendimento que possuía frutos prontos para a colheita no momento da aplicação das fontes de evidência. Essas pequenas diferenças identificadas nos casos está relacionada aos cuidados que cada produtor têm com as árvores frutíferas, o que indica que o produtor rural tem total influência no resultado da produção. Considerando que o produtor do caso 1 tem maior representatividade devido à quantidade de produção, o ano agrícola a ser considerado nesta pesquisa, para fim de construção do fluxo contábil, terá encerramento em maio, período em que normalmente já ocorreram a floração, a maturação dos frutos, a colheita e a comercialização dos produtos agrícolas.

Os equipamentos básicos utilizados no manejo de árvores frutíferas não variam de um empreendimento para outro e são caracterizados por enxadas, foices, tesouras de poda, machado, carriola, serrote, pulverizador, caixas para armazenagem e mangueiras para irrigação. Quanto aos insumos necessários para o negócio, destacam-se mudas para o plantio, água, adubos orgânicos, herbicidas e inseticidas.

Como pode ser observado no momento da aplicação das fontes de evidência, a fruticultura é uma atividade agrícola predominantemente familiar na região pesquisada.

\subsection{Discussão}

Com a interpretação e a análise das fontes de evidência, foi possível adquirir dados para a aplicação do CPC 27 e do CPC 29 no tocante ao registro da degeneração. O fato de os produtores rurais dos casos estudados não possuírem nenhuma forma de registro da produção não influenciou a construção do fluxo contábil para o ativo biológico e sua degeneração, que é apresentado posteriormente. Isso acontece porque os referidos pronunciamentos técnicos são claros no que se referem às formas de mensuração e registro dos ativos, e as informações fornecidas pelos produtores rurais entrevistados possibilitaram a estimativa de valores.

Sabe-se que, na fase de formação do imobilizado na fruticultura (da plantação à primeira floração ou colheita), o ativo biológico pode ser mensurado a valor de custo ou de mercado. A mensuração pelo método de custo é caracterizada pelo acúmulo dos custos com o ativo em andamento na conta específica do grupo de imobilizados "Ativos biológicos imaturos", e, quando o ativo estiver pronto para o início da produção, a soma desses custos acumulados será registrada como o valor do ativo biológico para produção em fase de operação na conta "Ativos biológicos maduros", no ativo imobilizado. Já no caso de 
mensuração inicial pelo valor justo, o crescimento do ativo é considerado um ganho, pois a tendência é que o valor de mercado do ativo aumente com a transformação biológica de crescimento. Ao final da fase de crescimento, o valor justo encontrado para o ativo corresponderá ao valor a ser registrado no ativo imobilizado, em conta específica de ativo biológico maduro ou em operação.

Como o objeto desta pesquisa é a degeneração de ativos biológicos para a produção, considera-se que o ativo não está mais em andamento, ou seja, está pronto para iniciar a produção e, independente de ter sido mensurado pelo custo ou valor justo, pertence ao subgrupo de ativos biológicos maduros (ou em operação) entre os ativos imobilizados.

Considerando a degeneração pelo método de custo à luz do CPC 27, as informações mais relevantes retiradas das fontes de evidência são o tempo que cada árvore frutífera produz em média, ou seja, a vida útil do ativo biológico, e a quantidade média de unidades produzidas por safra agrícola.

O CPC 27 permite a utilização do método de depreciação por unidades produzidas, que resulta em despesa baseada no uso ou produção do ativo, além disso, de acordo com o referido $\mathrm{CPC}$, a entidade deve selecionar o método de depreciação que melhor reflita o consumo dos benefícios futuros incorporados no ativo. Assim, o melhor método a ser utilizado na fruticultura é o de unidades produzidas, pois a produção de frutas não é constante durante todo o ano, o que é devido, principalmente, à influência de mudanças climáticas. Os cuidados que cada produtor rural têm com o cultivo também é um fator que contribui para a variação da produção.

Considerando agora a degeneração na fruticultura pelo método de valor justo à luz do CPC 29, nota-se uma dificuldade, pois a degeneração nesse método ocorre pela redução do valor de mercado do ativo, porém nenhum dos produtores entrevistados tem noção desse valor de mercado. Isso se deve ao fato de o ativo biológico, na fruticultura, não possuir mercado ativo na região pesquisada, remetendo à utilização de uma das formas de mensuração do valor justo previstas no CPC 29, quando não há mercado ativo para o produto.

De acordo com o CPC 29, quando não existir mercado ativo para a determinação do valor justo, a entidade deve utilizar: i) o preço de mercado da transação mais recente; ii) os preços de mercado de ativos similares; iii) os padrões do setor (relativização do ativo por informações do setor) ou o valor justo dos ativos combinados (terra nua + ativos biológicos) menos (terra nua). Entretanto pode não existir nenhuma dessas alternativas para a determinação do valor justo no mercado. Nessas circunstâncias, se for possível estimar o fluxo de caixa líquido esperado pelo ativo e a taxa de desconto, a entidade deve utilizar o valor presente do fluxo de caixa líquido esperado do ativo para a determinação do valor justo.

Tendo em vista a inexistência de preço de mercado e alternativas para estimar o valor justo nos casos estudados, optou-se por utilizar o valor presente dos benefícios futuros gerados pelo ativo como forma de mensuração do valor justo das goiabeiras formadas.

O objetivo do cálculo do valor presente dos fluxos de caixa líquidos esperados do ativo é determinar o valor justo do ativo biológico no local e condições atuais (CPC, 2009b). Para isso, utiliza-se uma taxa de desconto que reflita as avaliações atuais de mercado acerca do valor do dinheiro no tempo e dos riscos específicos do ativo para os quais as estimativas de fluxo de caixa futuros não tenham sido ajustadas (CPC, 2010).

Nos casos estudados, foram obtidas informações sobre a quantidade produzida por safra, o preço de venda dos produtos agrícolas resultantes do ativo biológico e os custos e

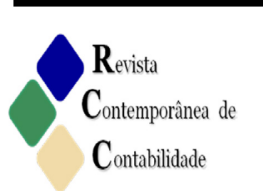

ISSN 2175-8069, UFSC, Florianópolis, v. 11, n. 22, p. 73-94, jan./abr. 2014 
despesas oriundos do cultivo de frutas. Dessa forma, o fluxo de caixa líquido esperado do ativo e a taxa de desconto podem ser estimados.

$\mathrm{Na}$ fruticultura, os dados que compõem o fluxo de caixa líquido esperado do ativo podem ser calculados com base no preço de venda dos produtos agrícolas, multiplicado pela quantidade produzida e nas principais despesas com a manutenção do ativo biológico. Já a taxa de desconto, pode ser estimada com base nas taxas implícitas em transações correntes de mercado para ativos semelhantes, ou com base no custo médio ponderado de capital de companhia aberta que tenha um ativo único, ou carteira de ativos, que se assemelhe ao ativo sob revisão em relação ao potencial de serviços e riscos (CPC, 2010).

No entanto, uma taxa específica de um ativo pode não estar diretamente disponível no mercado como acontece com os ativos biológicos. Em tais circunstâncias, a entidade deve valer-se de aproximações para estimar a taxa de desconto (CPC, 2010).

Como ponto de partida, para levar a efeito essa estimativa, o CPC 01 estabelece que a entidade pode considerar taxas como o custo médio ponderado de capital da entidade, apurado por meio de técnicas como o modelo de avaliação de ativos financeiros (CAPM); a taxa incremental de empréstimo da entidade e outras taxas de empréstimo de mercado. Mas, de acordo com o pronunciamento técnico em questão, essas taxas precisam ser ajustadas para refletir a forma como o mercado avaliaria os riscos específicos associados aos fluxos de caixa estimados do ativo e para excluir riscos que não são relevantes para os fluxos de caixa estimados do ativo ou para os quais os fluxos de caixa estimados tenham sido ajustados.

\subsection{Contabilização da Degeneração na Fruticultura: Um Comparativo entre os Métodos}

Com base em informações sobre o manejo de árvores frutíferas nos casos pesquisados, um fluxo contábil da degeneração na fruticultura é proposto, comparando os dois métodos de mensuração de acordo com os CPCs específicos.

Os Quadros 2 e 3 contêm os dados do fluxo de caixa líquido esperado do ativo biológico "árvore frutífera" que serviram de base para o cálculo do valor justo do ativo biológico para produção "Goiabeiras".

Os elementos que compõem o fluxo de caixa futuro na fruticultura são as receitas de vendas estimadas periodicamente para o ativo biológico durante toda a sua vida útil, ou seja, as entradas de caixa relacionadas às vendas de produtos agrícolas; as despesas (ou custos) dos produtos vendidos, entendidas também como os gastos gerados com a produção das frutas (adubação, depreciação de equipamentos) e outros gastos adicionais (como transporte para entrega dos produtos, por exemplo); e a estimativa do valor residual do ativo. Os valores estimados para esses elementos podem ser observados no Quadro 2.

Apesar da escassez de informações sobre a o cultivo de árvores frutíferas devido a não escrituração e ao controle da produção pelos produtores rurais, as estimativas foram feitas com base nas informações colhidas na aplicação das fontes de evidência. Dados adquiridos, como o tempo de vida útil do ativo biológico, a quantidade produzida por safra agrícola, o preço de venda dos produtos agrícolas e a média de gastos com o cultivo fazem com que as estimativas se aproximem da realidade dos casos estudados.

Com base nas informações dos produtores rurais entrevistados, uma goiabeira produz por 10 anos em média. Dessa forma, foram estimados os fluxos de caixa líquidos para esse período, tendo em vista o tempo de geração de benefício do ativo para a entidade. 
Quadro 2 - Dados para cálculo do valor justo do ativo biológico para produção

\begin{tabular}{|c|c|c|c|c|c|c|c|c|c|c|c|}
\hline \multirow{2}{*}{$\begin{array}{c}\text { Descrição } \\
\text { (Fluxo de Caixa) }\end{array}$} & \multicolumn{10}{|c|}{ Valores (\$) estimados: } \\
\cline { 2 - 10 } & Ano 1 & Ano 2 & Ano 3 & Ano 4 & Ano 5 & Ano 6 & Ano 7 & Ano 8 & Ano 9 & Ano 10 \\
\hline Receitas & $\underline{330.000}$ & $\underline{302.500}$ & $\underline{290.000}$ & $\underline{276.650}$ & $\underline{269.500}$ & $\underline{220.000}$ & $\underline{192.500}$ & $\underline{167.750}$ & $\underline{145.200}$ & $\underline{69.850}$ \\
Vendas prod. agrícolas & 330.000 & 302.500 & 290.000 & 276.650 & 269.500 & 220.000 & 192.500 & 167.750 & 145.200 & 69.850 \\
Despesas & $\underline{(22.062)}$ & $\underline{(21.577)}$ & $\underline{(21.036)}$ & $\underline{(19.004)}$ & $\underline{(19.381)}$ & $\underline{18.471)}$ & $\underline{(17.191)}$ & $\underline{(14.831)}$ & $\underline{(13.737)}$ & $\underline{(12.340)}$ \\
$\begin{array}{l}\text { Desp. Produtos Vendidos } \\
\text { Outras despesas }\end{array}$ & $(17.062)$ & $(16.927)$ & $(16.136)$ & $(14.538)$ & $(14.181)$ & $(13.471)$ & $(12.871)$ & $(11.267)$ & $(10.537)$ & $(9.383)$ \\
Valor residual do ativo & $(5.000)$ & $(4.650)$ & $(4.900)$ & $(4.466)$ & $(5.200)$ & $(5.000)$ & $(4.320)$ & $(3.564)$ & $(3.200)$ & $(2.957)$ \\
\hline
\end{tabular}

Fonte: Dados da pesquisa.

Aplicando uma taxa de desconto estimada em 2\% a.a., que reflete a taxa de empréstimos ao setor de fruticultura obtida em instituição financeira de fomento agrícola na região pesquisada, obtêm-se os valores presentes dos fluxos de caixa apresentados no Quadro 3.

Quadro 3 - Valor presente do ativo biológico para produção

\begin{tabular}{|c|c|c|c|c|c|c|c|c|c|c|}
\hline \multirow{2}{*}{$\begin{array}{c}\text { Descrição } \\
\text { (Fluxo de Caixa) }\end{array}$} & \multicolumn{10}{|c|}{ VP (R\$) estimados dos fluxos de caixa } \\
\hline & Ano 1 & Ano 2 & Ano 3 & Ano 4 & Ano 5 & Ano 6 & Ano 7 & Ano 8 & Ano 9 & Ano 10 \\
\hline Receitas & 323.529 & 290.754 & 260.693 & 255.582 & 244.094 & $\underline{195.354}$ & $\underline{167.583}$ & $\underline{143.173}$ & $\underline{121.497}$ & $\underline{57.301}$ \\
\hline Vendas prod. agrícolas & 323.529 & 290.754 & 260.693 & 255.582 & 244.094 & 195.354 & 167.583 & 143.173 & 121.497 & 57.301 \\
\hline Saidas & $(21.629)$ & $(20.739)$ & $(19.823)$ & $(17.557)$ & $(17.554)$ & $(16.402)$ & (14.966) & $(12.658)$ & $(11.495)$ & $(10.123)$ \\
\hline Desp. Produtos Vendidos & $(16.727)$ & $(16.270)$ & $(15.205)$ & $(13.431)$ & $(12.844)$ & $(11.962)$ & $(11.205)$ & $(9.616)$ & $(8.817)$ & (7.697) \\
\hline Outras despesas & $(4.902)$ & $(4.469)$ & (4.617) & $(4.126)$ & $(4.710)$ & $(4.440)$ & $(3.761)$ & $(3.042)$ & $(2.678)$ & $(2.426)$ \\
\hline Valor residual do ativo & & & & & & & & & & $\underline{2.461}$ \\
\hline Caixa líquido por ano & 301.900 & 270.014 & 240.871 & 238.025 & 226.540 & 178.952 & 152.617 & 130.515 & 110.002 & 49.639 \\
\hline $\begin{array}{l}\text { Valor presente total do } \\
\text { ativo (início do ano 1) }\end{array}$ & \multicolumn{10}{|c|}{ R\$ 1.899.075 } \\
\hline
\end{tabular}

Fonte: Dados da pesquisa.

Com base no Quadro 3, observa-se que a soma dos valores presente dos fluxos de caixa líquidos esperados do ativo é de R \$ 1.899.075,00. Esse valor representa o valor justo inicial do ativo biológico, considerando que não existe mercado ativo para mensurá-lo, mas apenas estimativas de benefícios futuros. Esse é o valor que será registrado no reconhecimento inicial do ativo no grupo de ativos imobilizados. No registro do reconhecimento inicial do ativo mensurado a valor justo, além do lançamento correspondente ao valor do ativo biológico, registra-se também uma provisão para as despesas estimadas de vendas como prevê o CPC 29, que, nesta pesquisa, equivale a uma média de $3 \%$ do valor justo do ativo. Além disso, as despesas com a formação do ativo biológico que é estimada em $\mathrm{R} \$ 350.000,00$ (gastos entre a preparação do terreno e a primeira floração) também deve ser registrada no momento do reconhecimento inicial. Toda esta contabilização é demonstrada no Diário apresentado na Figura 2.

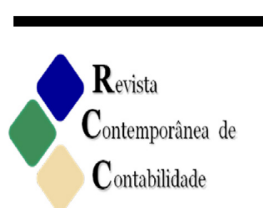


Figura 2 - Fluxo contábil do ativo biológico para a produção mensurado a valor justo

\begin{tabular}{|lllr|}
\hline \multicolumn{4}{|c|}{ Ano 1 - Reconhecimento inicial do ativo a valor justo } \\
\hline D- $\quad$ Ativo Biológico Maduro - Goiabeiras & $=$ & 1.899 .075 \\
C- & Ganhos & 1.899 .075 \\
& & & \\
D- & Despesas estimadas de vendas & $56.972,25$ \\
C- & Provisão despesa de vendas & & $56.972,25$ \\
& & & \\
D- & Desp. com a cultura em formação & 350.000 \\
C- & Caixa/Bancos/Fornecedores & $=$ & 325.000 \\
C- & Depreciação acumulada máq./equip. & $=$ & 25.000 \\
\hline
\end{tabular}

O ativo biológico para a produção deve ser mensurado pelo valor justo menos despesas estimadas de venda no momento do reconhecimento inicial e final de cada período de competência como preceitua o item 12 do CPC 29. Dessa forma, utilizando o mesmo cálculo para a definição do valor presente dos fluxos de caixa esperados durante os dez anos (Quadro 3), calculou-se o valor presente para os nove anos restantes (a partir do primeiro ano de produção), supondo que haveria nova avaliação do ativo ao final do Ano 1. Esse valor é igual a R\$ 1.639.441,00. Observa-se que houve uma redução de R\$ 259.634,00 no valor do ativo, em comparação ao valor do reconhecimento inicial. Essa diferença será registrada como perdas no resultado do exercício do período e representa o valor da degeneração do ativo no primeiro ano.

Demonstra-se agora a degeneração do ativo pelo método de custo, à luz do CPC 27, utilizando o método de unidades produzidas. $\mathrm{O}$ custo total de formação do ativo biológico será registrado no grupo de ativos biológicos maduros, pois representa o valor das goiabeiras formadas com base no custo histórico de formação. No ano 1, a quantidade produzida foi $140.426 \mathrm{~kg}$, sabendo que a goiabeira produz por dez anos e que o total de frutos produzidos durante toda a vida útil do ativo equivale a $960.000 \mathrm{~kg}$ em média, calcula-se uma taxa de depreciação de 14,63\% a.a. (140.426/960.000). Essa taxa será aplicada ao valor do custo do ativo que, como mencionado anteriormente, é estimado em $\mathrm{R} \$ 350.000$, reduzido do valor residual estimado de $\mathrm{R} \$ 3.000$. Assim, o valor da degeneração do ativo biológico, no primeiro ano, é de $\mathrm{R} \$ 50.766,10$.

Entretanto, no Ano 2, houve uma redução na quantidade produzida no ativo que agora é de $128.723 \mathrm{~kg}$, logo a taxa de depreciação do segundo ano será de $13,41 \%$. O valor da degeneração no segundo ano é igual a $\mathrm{R} \$ 46.532,70$.

A Figura 3 demonstra um comparativo da contabilização nos dois métodos apresentados, com lançamentos no Diário.

Com base na Figura 3, observa-se que, no método do valor justo, a degeneração que explica a redução do valor justo do ativo é creditada diretamente na conta do imobilizado que registra o ativo biológico, reduzindo-a e tendo como contrapartida a conta de resultado "Perdas", ou seja, a degeneração pelo valor justo tem influência direta no resultado econômico da produção rural. Observa-se também que, como houve redução no valor justo do ativo biológico, consequentemente a provisão de despesas estimadas de vendas também é reduzida na mesma proporção. Dessa forma, faz-se um lançamento inverso ao da provisão de 
despesas estimadas de vendas do reconhecimento inicial, contabilizando apenas o valor da diferença na redução da provisão.

Figura 3 - Comparação da contabilização da degeneração do ativo biológico para a produção

\begin{tabular}{|c|c|c|c|c|}
\hline \multicolumn{5}{|c|}{ Valor Justo - CPC 29} \\
\hline \multirow{4}{*}{ 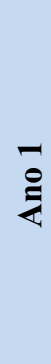 } & & Perdas & & $59.634,00$ \\
\hline & & $\begin{array}{l}\text { Ativo Biológico Maduro } \\
\text { - Goiabeiras }\end{array}$ & $=$ & $59.634,00$ \\
\hline & & $\begin{array}{l}\text { Provisão despesas de } \\
\text { vendas }\end{array}$ & $=$ & $7.789,02$ \\
\hline & & $\begin{array}{l}\text { Despesas estimadas de } \\
\text { vendas }\end{array}$ & $=$ & $7.789,02$ \\
\hline
\end{tabular}

Fonte: Dados da pesquisa.

\begin{tabular}{|c|c|c|}
\hline \multicolumn{3}{|c|}{ Custo - CPC 27} \\
\hline $\overrightarrow{\mathrm{e}}$ & $\begin{array}{l}\text { D - Estoque de produtos agrícolas } \\
\text { C - Depreciação acumulada - } \\
\text { Goiabeiras }\end{array}$ & $\begin{array}{l}=50.766,10 \\
=50.766,10\end{array}$ \\
\hline$\stackrel{N}{\stackrel{2}{ٍ}}$ & $\begin{array}{l}\text { D - Estoque de produtos agrícolas } \\
\text { C - Depreciação acumulada - } \\
\text { Goiabeiras }\end{array}$ & $\begin{array}{l}=46.532,70 \\
=46.532,70\end{array}$ \\
\hline
\end{tabular}

Com base no método de custo, como apresentado na Figura 3, constata-se que o valor da degeneração (resultante da redução do potencial produtivo do ativo) é creditado em conta específica de depreciação acumulada e funciona como redutora da conta que registra o ativo biológico no imobilizado. Já a conta debitada é a de estoque de produtos agrícolas, ou seja, a degeneração não tem influência direta no resultado do período, mas apenas quando da venda dos produtos.

\section{Considerações Finais}

Esta pesquisa buscou evidenciar a contabilização da degeneração na fruticultura por meio de um comparativo entre os métodos de custo e valor justo adotando os procedimentos normatizados pelo CPC 27 e CPC 29, que são as principais normas contábeis no que se refere à mensuração de ativos biológicos. Porém concentrou-se na demonstração da diferença entre os dois métodos de avaliação de ativos biológicos, gerando oportunidades de pesquisas futuras baseadas na busca de informações que auxiliem na definição do melhor método a ser adotado na fruticultura, bem como na avaliação da relevância da aplicabilidade do CPC 29 para esse setor.

Com base nos preceitos do CPC 29, tornou-se possível propor a contabilização da degeneração na fruticultura utilizando o método de mensuração pelo valor justo em empreendimentos que possuem na fruticultura sua principal fonte de receita, mesmo localizados numa região onde não há mercado para o ativo biológico. Tal proposta torna-se relevante se considerado o atual processo de convergência das normas brasileiras de contabilidade aos padrões internacionais, que se distancia do uso da contabilidade apenas para atendimento às necessidades do fisco e vislumbra-se a utilização desse instrumental como apoio à decisão.

Conforme exposto ao longo do trabalho, outros autores, a exemplo de Marion (2012), já evidenciaram a degeneração de ativos biológicos pelo método de mensuração do custo, em que o valor referente à depreciação do ativo é considerado um custo de formação do estoque de produtos agrícolas e não influencia diretamente o resultado econômico do exercício, como

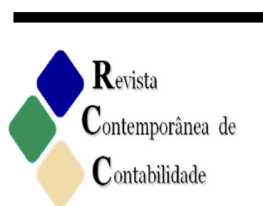


acontece no método de valor justo. Dessa forma, utilizando os preceitos do CPC 27, demonstrou-se a contabilização da depreciação na fruticultura.

A partir do modelo proposto de contabilização da degeneração, aplicando o CPC 29, foi possível traçar um comparativo com a contabilização da degeneração do ativo biológico na fruticultura, mensurado a valor de custo, e demonstrar as possíveis formas de reconhecimento da degeneração no cultivo de árvores frutíferas, alcançando o objetivo geral desta pesquisa.

A pesquisa tem como limitações o fato de que os produtores entrevistados não possuem qualquer registro ou escrituração da produção e não possuem informações sobre o valor de mercado das árvores frutíferas, apenas dos produtos agrícolas negociados. Dessa forma, os valores das entradas e saídas de caixa utilizados na proposta, assim como a taxa de desconto, podem desviar-se sutilmente da realidade dos casos estudados, pois foram baseados em estimativas. Na tentativa de mitigar essa limitação, informações adicionais sobre os casos foram solicitadas em instituição financeira de fomento agrícola na região pesquisada, contudo poucos dados da produção foram obtidos, eventualmente por se tratar de pequenos empreendimentos. A escolha do uso de casos múltiplos ajudou nesse sentido, pois permitiu o confronto entre os casos estudados na busca de dados que melhor se aproximassem da realidade do setor de fruticultura.

Apesar da escassez de informações sobre os valores reais de fluxo de caixa e da ausência de dados para a melhor definição da taxa de desconto, o principal achado da pesquisa é que os modelos de contabilização da degeneração apresentados confirmam que há possibilidade de mensuração e evidenciação das transformações biológicas nas atividades rurais em acordo com as normas atuais de contabilidade. Isso possibilita o uso de informações relevantes para a tomada de decisão e reduz distorções na mensuração do patrimônio da entidade. Essa ideia geral foi transmitida pela pesquisa e remete à possibilidade de replicação dos métodos demonstrados em outros tipos de ativos biológicos, que não sejam os cultivados na fruticultura.

\section{Referências}

ARGILÉS, J. M.; GARCIA-BLANDON, J.; MONLLAU, T. Fair value versus historical costbased valuation for biological assets: predictability of financial information. Revista de

Contabilidad-Spanish Accounting Review, v. 14, p. 87-113, 2011.

AZEVEDO, G. M. D. C. Factores influentes na aplicação da IAS 41 “agricultura” nas empresas vitivinícolas portuguesas. Revista de Educação e Pesquisa em Contabilidade, v. 5, p. 86-116, 2011.

BARDIN, L. Análise de conteúdo. São Paulo: Edições 70, 2011.

CPC. CPC 01 Redução ao Valor Recuperável de Ativos. In: (Ed.). Brasília: Conselho Federal de Contabilidade, 2010. Disponível em: $<$ http://www.cpc.org.br/index.php $>$. Acesso em: 15 out. 2013. 
CPC. CPC 27 Imobilizado. In: (Ed.). Pronunciamentos técnicos contábeis 2009. Brasília: Conselho Federal de Contabilidade, 2009a. Disponível em: < http://www.cpc.org.br/index.php >. Acesso em: 7 ago. 2013.

CPC. CPC 29 Ativo biológico e produto agrícola.In: (Ed.). Pronunciamentos técnicos contábeis 2009. Brasília: Conselho Federal de Contabilidade, 2009b. Disponível em: < http://www.cpc.org.br/index.php >. Acesso em: 7 ago. 2013.

CREPALDI, S. A. Contabilidade rural: uma abordagem decisorial. 4. ed . São Paulo: Atlas, 2006.

FIGUEIREDO, A. M.; SANTOS, M. L. D.; LIMA, J. F. D. Importância do Agronegócio para o Crescimento Econômico de Brasil e Estados Unidos. Revista Gestão \& Regionalidade v. $28,2012$.

FREIRE, M. D. D. M.; MACHADO, M. R. R.; MACHADO, L. S.; SOUZA, E. S.; OLIVEIRA, J. J. D. Aderência às normas internacionais de Contabilidade pelas empresas brasileiras. Revista de Contabilidade e Organizações, v. 6, p. 3-22, 2012.

HENDRIKSEN, E. S.; BREDA, M. F. V. Teoria da Contabilidade. São Paulo: Atlas, 2007.

IUDÍCIBUS, S. D.; MARTINS, E.; GELBCKE, E. R.; SANTOS, A. D. Manual de Contabilidade Societária: aplicável a todas as sociedades de acordo com as normas internacionais e do CPC. São Paulo: Atlas, 2010.

MARION, J. C. Contabilidade Rural: Contabilidade agrícola, Contabilidade da pecuária, imposto de renda pessoa jurídica. 13. ed. São Paulo: Atlas, 2012.

OLIVEIRA, D. D. L.; FERREIRA, E. P. D. S.; PORTO, W. S. Mensuração e evidenciação do ativo biológico na piscicultura: uma proposta de fluxo contábil à luz do CPC 29. R.E.S.C Revista Eletrônica Saber Contábil v. 2, p. 39-53, 2012.

PEREIRA, B. A. D.; BRAGA, A. L.; STEFFANELLO, M.; VENTURINI, J. C. Avaliação de estratégias de desenvolvimento econômico e social por meio da implantação de cadeias produtivas de fruticultura no Espírito Santo. Revista Organizações Rurais \& Agroindustriais, v. 12, p. 275-289, 2010.

SEVERINO, A. J. Metodologia do trabalho científico. 23. ed. São Paulo: Cortez, 2007.

SILVA, A. F. S. D.; SILVA, E. P. D.; DENBER, M. W. D. S. Mensuração do fair value de ativos tangíveis: estoque e ativo imobilizado. Revista Pensar Contábil, v. 13, p. 48 - 55, 2011.

SILVA FILHO, A. C. D. C. E.; CAMPOS, S. J. B.; PAUlO, E.; CÂMARA, R. P. D. B. Sensibilidade do Patrimônio Líquido a adoção do fair value na avaliação dos ativos biológicos 
e produtos agrícolas: um estudo nas empresas do agronegócio listadas na Bovespa no período de 2008 e 2009. Revista Custos e @gronegócio on line, v. 8, n. Especial, 2012.

SILVA FILHO, A. C. D. C. E.; MACHADO, M. A. V.; MACHADO, M. R. Custo histórico $\mathrm{X}$ valor justo: qual informação é mais value relevant na mensuração dos ativos biológicos?

Revista Custos e @gronegócio on line, v. 9, 2013.

SOARES BRASIL, A. M.; OLIVEIRA, K. C.; ARAÚJO NETO, P. L. D.; NASCIMENTO, I. A. D.; MORAES JUNIOR, V. F. D. Representatividade do custo de controle da mosca minadora na produção de melão: um estudo de caso na empresa Santa Júlia Agro Comercial Exportadora de Frutas Tropicais Ltda. Revista Custos e @gronegócio on line, v. 8, n. Especial, 2012.

WANDERLEY, C. A. N.; SILVA, A. C. D.; LEAL, R. B. Tratamento contábil de ativos biológicos e produtos agrícolas: uma análise das principais empresas do agronegócio brasileiro. Revista Pensar Contábil, v. 14, p. 53-62, 2012.

YIN, R. K. Estudo de caso: planejamento e métodos. 4. ed. Porto Alegre: Bookman, 2010. 
